\title{
Pancreatic islet regenerative capability of Dillenia excelsa in alloxan-induced diabetic rats
}

\author{
Amal Hazirah Afiqah Matusin, Nurul Izzati Abd Ghani, Norhayati Ahmad* \\ Environmental and Life Sciences, Faculty of Science, Universiti Brunei Darussalam, Gadong, Negara Brunei Darussalam.
}

\begin{tabular}{l}
\hline ARTICLE INFO \\
\hline Received on: $17 / 09 / 2020$ \\
Accepted on: 02/12/2020 \\
Available online: 05/03/2021 \\
\hline Key words: \\
Dillenia excelsa, diabetes, \\
pancreatic islet regeneration, \\
antidiabetic, islet \\
morphometry.
\end{tabular}

\begin{abstract}
Dillenia excelsa is a relatively understudied plant with limited reports on its biological activities apart from its traditional use. Our aim was to investigate the blood glucose lowering effects and pancreatic islet regeneration in alloxan-induced Wistar rats following treatment with D. excelsa plant extract. Alloxan ablation of the pancreatic islets leads to a significant size reduction and loss of morphology of the islets. In this study, alloxan-induced diabetic animals were treated with $D$. excelsa extract at 250 and $500 \mathrm{mg} / \mathrm{kg}$ b.w. for a 12 -week period. In another group, animals were treated with the plant extract for a period of 5 weeks prior to alloxan-induced damage to determine the protective effects of $D$. excelsa. An increase in the islet to tissue ratio was observed in alloxan-induced rats treated with $500 \mathrm{mg} /$ $\mathrm{kg}$ b.w. of extract at weeks 8 and 12 relative to control animals which was accompanied by a significant reduction in blood glucose levels. $D$. excels $a$ was also able to effectively prevent adverse damage of the pancreatic islets following a pretreatment period with the extract for a period of 5 weeks. Our findings indicate that the methanol extract of $D$. excelsa is capable of lowering blood glucose levels where one of the mechanisms of recovery is via the regeneration of pancreatic islets.
\end{abstract}

\section{INTRODUCTION}

Plants have been known to have an abundance of active components along with having minimum side effects, good affordability, and ease of availability (Surya et al., 2014). Different mechanisms of the antidiabetic action of these plants include the decrease of glucose absorption from the intestine, increased glucose uptake by tissues, inhibition of glucose production in the liver, enhanced insulin secretion from $\beta$-cells, and in particular interest of the current study-the increase in pancreatic tissue regeneration (Asgary et al., 2008; Hosseini et al., 2015; Jelodar et al., 2007; Kamyab et al., 2010).

Dillenia excelsa belongs to the Dilleniaceae family and is found to be selectively distributed around Borneo, Malaysia, and some parts of Indonesia. It is locally known as "Simpor laki" or "Simpoh" (Quattrocchi, 2012; Tan and Latiff, 2014). To date, there

"Corresponding Author

Norhayati Ahmad, Environmental and Life Sciences, Faculty of Science, Universiti Brunei Darussalam, Gadong, Negara Brunei Darussalam. E-mail:norhayati.ahmad@ubd.edu.bn are very limited studies available on the medicinal values of $D$. excelsa. Previously, several ethnobotanical studies have reported that the bark and fruits of $D$. excelsa were used as a treatment for diarrhea (Goh et al., 2017; Quattrocchi, 2012). Despite the lack of scientific studies on $D$. excelsa, there is reported literature on the biological activities of other Dillenia species where more extensive studies have been carried out, one of which is Dillenia indica, where extracts of the plant were reported to inhibit $\alpha$-amylase and $\alpha$-glucosidase activities (Kumar et al., 2013) and reduced blood glucose levels and other biochemical parameters in diabetic-induced animal models (Kaur et al., 2016; Kumar et al., 2011a, 2011b).

In addition to the control of blood glucose levels, there has been an interest in pancreatic regeneration to compensate for the loss in $\beta$-cell mass, especially in type 1 diabetic patients and in animal models. It was reported that rapid pancreas and $\beta$-cell regeneration can be observed in young rodents and children, but the regenerative capacity seemed to decline in adults (Menge et al., 2008; Rankin and Kushner, 2009). Several mechanisms have been suggested for pancreatic islet and $\beta$-cell regeneration in response to injury and during normal homeostasis which is via self-replication and regeneration (Dor et al., 2004). Certain 
stimuli such as depletion in $\beta$-cell mass or presence of compounds targeting the differentiation mechanism of pancreatic stem cells could trigger $\beta$-cell regeneration (Zhou and Melton, 2018).

In this study, we seek to determine the capability of the understudied medicinal plant, D. excelsa, in pancreatic islet regeneration following its ablation in alloxan-induced diabetic animals. The monitoring of blood glucose levels was also used as a measure to determine if the regenerated islets had the capability to perform normally when subjected to a glucose challenge. The regeneration of pancreatic islets was based on the determination of islet morphometry via histopathological evaluation. The possible protective effects of pretreatment with $D$. excelsa in protecting the islets from ablation by alloxan were also evaluated in the present study.

\section{MATERIALS AND METHODS}

\section{Plant materials}

The leaves from $D$. excelsa were collected from Brunei Muara District, Brunei Darussalam, between August and December 2016. Species identification was confirmed by a taxonomist from the Environmental and Life Sciences, Faculty of Science, University of Brunei Darussalam. A voucher specimen of the plant was prepared and deposited in the Universiti Brunei Darussalam Herbarium (voucher number: UBDH/S/00757).

\section{Preparation of extract}

D. excelsa leaves were shade-dried for a period of 2-3 weeks and ground prior to solvent extraction. The coarse materials were then placed into a Soxhlet extraction apparatus using methanol (Merck, Germany) as the solvent, to obtain the methanolic extracts of the plants. The extracts were then dried at a temperature of $60^{\circ} \mathrm{C}$ in a rotary evaporator to remove the methanol, leaving a semisolid phase, and stored in the refrigerator. Prior to administration of extracts to the animals, the crude extracts were dissolved in a small amount of methanol solvent before making it up to a concentration of $100 \mathrm{mg} / \mathrm{ml}$ extract solution with $0.9 \%$ saline. The extract was then administered via oral gavage at either 250 or $500 \mathrm{mg} / \mathrm{kg} \mathrm{b.w}$. at the same time of day in the respective groups for a period of up to 12 weeks.

\section{Antidiabetic activity}

\section{Ethical statement}

All work involving animals was approved by the University Research Ethics Committee of University Brunei Darussalam (approval reference: UBD/FOS/M2). All procedures were carried out in accordance with the Universiti Brunei Darussalam guidelines on the care and use of animals for research and internationally accepted guidelines. The investigators declare that every effort has been taken to ameliorate harm to the animals via the monitoring for signs of pain and distress in accordance with the Universiti Brunei Darussalam guidelines on care and use of animals for research.

\section{Animals}

Male Wistar rats weighing between $180 \mathrm{~g}$ and $250 \mathrm{~g}$ and aged 8-10 weeks were used in this study. Only male animals were used in this study in order to reduce gender variations. The animals were obtained from the Universiti Brunei Darussalam's animal facility. Rats were housed in cages with wood shavings and kept under normal 12-hours light-dark cycle, a temperature of $25^{\circ} \mathrm{C} \pm 2{ }^{\circ} \mathrm{C}$, and standard humidity conditions and fed with standard pellet rat diet (Specialty Feeds, Western Australia). Upon completion of the experiments, animals were euthanized with $\mathrm{CO}_{2}$ asphyxiation.

\section{Induction of diabetes}

Diabetes was induced in overnight fasted rats via a single intraperitoneal injection of alloxan monohydrate (Sigma Aldrich, United Kingdom) in $0.9 \%$ saline at a dose of $120 \mathrm{mg}$ / $\mathrm{kg}^{-1}$ body weight. After 3 days of alloxan administration, animals with a postprandial blood glucose reading of $>20.0 \mathrm{mmol} / \mathrm{l}$ were selected and used in the study.

Blood glucose and the body weight of the animals were monitored weekly. For animals in the protective group, the blood glucose reading was only recorded at 72 hours following alloxan administration. The blood was drawn from the tip of the tail vein via a single touch strip and readings were measured in mmol/l. Animals were considered diabetic when blood glucose reading was > $11.1 \mathrm{mmol} / \mathrm{l}$ (200 mg/dl) (Qinna and Badwan, 2015) and was selected for the study.

\section{Experimental design}

Animals were randomly allocated into four main groups. The number of animals $(n)$ used in these studies was based on previous studies in our laboratory, which was also the minimum required to detect significant differences between the groups.

The rats were divided into four main groups as follows:

(1) Non-diabetic control $(n=6)$.

(2) Alloxan-only treated control $(n=6)$ : rats were treated with only alloxan at $120 \mathrm{mg} / \mathrm{kg}$ b.w.

(3) Treatment group ( $n=6$ each): rats were injected with alloxan prior to extract administration at the doses below for a period of 12 weeks:

(i) Diabetic rats administered with $D$. excelsa extract $250 \mathrm{mg} / \mathrm{kg}$ b.w.

(ii) Diabetic rats administered with $D$. excelsa extract $500 \mathrm{mg} / \mathrm{kg}$ b.w.

(4) Protective group ( $n=5$ each): animals were pretreated with $D$. excelsa extract at the doses below for a period of 5 weeks prior to a single intraperitoneal injection of alloxan at $120 \mathrm{mg} \mathrm{kg}^{-1}$ b.w. alloxan administration.

(i) Administration of $D$. excelsa $250 \mathrm{mg} / \mathrm{kg}$ b.w. (5-week duration), followed by alloxan.

(ii) Administration of $D$. excelsa $500 \mathrm{mg} / \mathrm{kg}$ b.w. (5-week duration), followed by alloxan.

In the first part of the study, animals were treated with alloxan, followed by the administration of the plant extract. At the end of the experimental period, intraperitoneal glucose tolerance test (IPGTT) was carried out for all animals.

\section{Intraperitoneal glucose tolerance test (IPGTT)}

Animals were fasted overnight prior to carrying out the IPGTT at the end of the experimental period. Animals were loaded 
with glucose at $2 \mathrm{~g} / \mathrm{kg}$ body weight by intraperitoneal injection and blood glucose readings were recorded at 15, 30, 60, 90, and 120 minutes following glucose administration. All blood glucose readings were measured using a single touch glucometer (Style Free Optium, Abbott Diabetes Care Ltd.).

\section{Histological analysis of pancreatic islet}

At the end of the experimental period, animals were culled and pancreatic tissues were collected for histological analysis. Pancreatic tissues were fixed in 3.7\% formaldehyde, followed by tissue processing and embedding in paraffin wax (Thermo Fisher Scientific, Waltham, MA).

Tissues were sectioned at $10 \mu \mathrm{m}$ thickness using a microtome (Thermo Scientific Shandon Finesse) starting at a random initial point. Tissue sections were collected after every 50 -section intervals from the starting point and a second section was also sampled. Two sampled sections per pancreatic tissue block were selected for further staining with hematoxylin (Supplementary F1).

\section{Determination of ratio of islet to tissue area}

Quantitative measurement of the ratio of islet size area relative to the area of the whole pancreatic tissue was carried out using the Image J Software version 1.50s (National Institute of Health). In each sampled section, the tissue was further divided into smaller numbered segments (Supplementary F2a) where the islet and tissue area of each segment were determined by dividing the measured total islet area $(\mu \mathrm{m})$ with the total area of the whole pancreas tissue section $(\mu \mathrm{m})$ for each individual animal (Supplementary F2b). The total islet area was obtained by the sum of all the numbered segments in the tissue section (Supplementary F3). These were then compiled and summed up to obtain the total area of the islet and area of the non-islet sections. The ratio obtained from each individual animal was then used to determine the average ratio of the islet size relative to pancreatic tissue area for all animals from the same group $(n=3)$. The calculation for the determination of the ratio of the islet to tissue size is as follows:

Ratio of the islet size to pancreas tissue area of one individual animal $=$ Total islet size $(\mu \mathrm{m}) /$ Total pancreas tissue area $(\mu \mathrm{m})$

\section{Statistical analysis}

Data were represented as mean \pm SEM and analyzed using a Graph Pad Prism Software (Windows Version 6.01, GraphPad Software, Inc.). Two-way analysis of variance analysis was carried out to determine the statistical differences among the groups, followed by a post-hoc Dunnett's and Sidak's multiple comparisons test. A significant difference was indicated by $p<0.05$.

\section{RESULTS}

\section{Effect of $D$. excelsa leaf extract on blood glucose}

Animals that received a high dose of the plant extract $\left(500 \mathrm{mg} / \mathrm{kg}^{-1}\right.$ b.w.) resulted in a significant decrease $(p<0.05)$ in blood glucose (Table 1).

In the protective group, a protective effect was observed against hyperglycemia and also islet damage. The animals that have been pretreated with $500 \mathrm{mg} / \mathrm{kg}$ b.w. of the $D$. excels $a$ extract showed moderately high blood glucose $(11.20 \mathrm{mmol} / \mathrm{l})$ when compared to that of the normal control animals but still lower than the alloxan-only controls. Animals pretreated with the lower dose of plant extract, however, were not effective in protecting against alloxan-induced diabetes.

According to the IPGTT data, animals treated with a higher extract concentration were able to reduce the blood glucose from the initial peak. For animals in the protective group, a similar trend was also observed where there was improved glucose clearance compared to the animals pretreated with a low dose of the extract (Supplementary F4).

\section{Islet morphometry and morphology}

The islet morphology of animals in the alloxan-only control group showed damage with a reduced number of islets compared to the islets from normal animals. Tissue sections taken 72 hours following alloxan administration showed severe atrophy and destruction in both endocrine and exocrine tissues of the pancreas (Supplementary F5a). The sizes of the islets were significantly reduced and lost their integrity and appeared shrunken, indicating damaged islets (Cheekati et al., 2017). Following a recovery period of 4,8 , and 12 weeks, the islets were observed to regain their structural architecture [Supplementary, F5(b), 5(c) and 5(d)]; however, damaged and distorted pancreatic islets could still be observed.

The pancreatic islets of the alloxan-induced rats administered with the high dose of $D$. excelsa extract showed considerable improvement in islet structure and size during the different time periods of 4, 8, and 12 weeks [Supplementary F6(d), $7(\mathrm{~d})$, and $8(\mathrm{~d})$ ]. On the contrary, the alloxan-induced rats treated with a low dose of the extract showed pancreatic islet undergoing a lesser change during the experimental period [Supplementary F6(c), 7(c), and 8(c)]. The recovery of the islets in the low-dose treatment group became evident from weeks 8 and 12, where the pancreatic islets were observed to be more regular in shape; however, the blood glucose of animals remained consistently high throughout the study (Table 1). This might indicate that although the pancreatic islets of animals in the low-dose treatment group appear to have shown recovery, it was not significant enough for the cells to regain their normal function and bring about the lowering of the blood glucose. Similarly, animals in the lowdose and high-dose protective groups showed an improvement of islet morphology compared to the alloxan-only control group (Supplementary F9).

\section{Ratio of islets size to tissue area}

The ratio of islet size to tissue area for the treated animals in the different groups is shown in Table 2. The ratios showed an increase for animals receiving the plant extract following the 12week treatment period.

The islet to tissue ratio in the tissue sections of the high dose treatment group rapidly increased from week 0 to 4 and was comparable with that of the normal control group (Table 2). These ratios were significantly higher $(p<0.05)$ when compared to that of the alloxan-only control group, suggesting that the high dose of $D$. excelsa extract has the ability to enhance the regeneration of islets and is complemented with the reduction of blood glucose levels in weeks 0 to 12. For animals in the low-dose-treated group, 
the ratio of islet to tissue area was lower at all three time points of 4,8 , and 12 weeks compared to the controls and is complemented with the high glucose levels in weeks 4,8 , and 12 (Table 1).

As seen in Table 2, the ratios of the rats in the high-dose protective group at 72 hours after alloxan administration were also higher compared to that of the alloxan-only control and the low-dose pretreated rats. Based on these findings, we propose that $D$. excelsa extract has the potential to stimulate the regeneration and protection of islets and appears to exert its effect in a dosedependent manner.

\section{DISCUSSION}

Previous studies have reported the antidiabetic effects of few species of genus Dillenia, such as D. indica and Dillenia pentagyna (Kaur et al., 2016; Smitha et al., 2012; Yadav et al., 2017). The present study determines the antidiabetic activity of the methanol extract of $D$. excelsa administered at $250 \mathrm{mg} / \mathrm{kg}^{-1}$ and $500 \mathrm{mg} / \mathrm{kg}^{-1}$ b.w with an evaluation of the islet morphometry.

Numerous studies have reported that rapid pancreatic and $\beta$-cell regeneration can be observed in young rodents and children, but the capacity seemed to decline in adults (Menge et al., 2008; Rankin and Kushner, 2009). Our investigations have shown that animals receiving the higher dose of $D$. excels $a$ extract showed regeneration of the islets compared to its alloxan-onlytreated controls. This was accompanied by an improvement of glucose clearance that complemented the IPGTT results which has shown an improvement.

The ability of plant extracts to recover islets has been previously reported where treatment of alloxan or streptozotocin (STZ)-induced rats with medicinal plant extracts such as Gymnema sylvestre, Juglans regia, Leucaena. leucocephala, and Momordica charantia was shown to increase islets diameter, recover the function $\beta$-cells of the Islet of Langerhans, and regenerate new islet cells in response to the damage of the existing $\beta$-cells (Hosseini et al., 2015). M. charantia was known to mimic the insulin produced in animals and induces significant regeneration of the pancreatic islets (Joseph and Jini, 2013). Interestingly, Singh and Gupta (2007) claimed that the alkaloid compounds present in the acetone extract of $M$. charantia fruit were not only able to regenerate the existing islets but also had the ability to stimulate the birth of newly formed islets due to enhanced $\beta$-cell division and differentiation.

Gymnema sylvestre is another commonly used antidiabetic plant in India (Kanetkar et al., 2007) where its leaf extracts have been found to have the capacity to regenerate pancreatic islets and $\beta$-cells in alloxan- and STZ-induced diabetic rats (Ahmed et al., 2010; Hafizur et al., 2015). The regenerative capacity of $G$. sylvestre extract was known to be due to the action of its active constituents, gymnemic acid, and its derivatives (Ahmed et al., 2010; Kanetkar et al., 2007). Immunohistochemical studies have reported an increase in the appearance of insulinpositive cells in the islets of the treated animals, when compared to the diabetic untreated animals indicating the regeneration of the pancreatic $\beta$-cells following $G$. sylvestre extract treatment (Hafizur et al., 2015).

Similarly, our study has shown that the treatment with $D$. excelsa extract at a high dose stimulated moderate islet regeneration and protection in the pancreas of the rats and with this complements the reduction and maintenance of their blood glucose levels to near-normal level (Table 1). Based on the islet to tissue ratio we have obtained, the treatment with the $D$. excelsa extract at $500 \mathrm{mg} / \mathrm{kg}$ b.w. was able to reduce blood glucose concentration, stimulate islet regeneration, and increase the number of islets in the pancreas tissue of alloxan-induced diabetic animals following a recovery time period of up to 12 weeks. In addition, pretreatment with $D$. excelsa extracts prior to alloxan administration was found to protect the islets and the beta cells from the severe effects of alloxan. The regeneration of the islet cells observed could be attributable to several factors. Previous studies have reported that the ducts are a source of regenerating beta cells in the pancreas. Other studies suggested that $\beta$-cells could be regenerated from stem cells (neogenesis) that are present in the duct and acini or within the islets of the pancreas (AguayoMazzucato and Bonner-Weir, 2018; Xu et al., 2008; Zhou and Melton, 2018). New islets have been reported to emerge from the existence of these stem cells, which developed into small islet clusters surrounding the pancreatic ducts (Aguayo-Mazzucato and Bonner-Weir, 2018; Zhou and Melton, 2018). In the context of the present study, the presence of factors that are present in the plant extract could contribute to the regeneration of pancreatic islets.

\section{CONCLUSION}

D. excelsa is shown to exert antidiabetic and protective effects on pancreatic islets as seen from its ability to lower hyperglycemia and contribute to islet recovery in treated animals following alloxan ablation. Investigations will require the active components present in the plant extracts that contribute to the regeneration of the islets to be identified and undergo further analysis in order to understand the detailed mechanism of action. The islet protective capabilities could justify its use in protecting the pancreatic islets from damage.

\section{ACKNOWLEDGMENT}

This study was supported by Universiti Brunei Darussalam grant ref no. (UBD/RSCH/1.13/FICBF(b)/2019/010).

\section{AUTHOR CONTRIBUTIONS}

All authors made substantial contributions to conception and design, acquisition of data, or analysis and interpretation of data; took part in drafting the article or revising it critically for important intellectual content; agreed to submit to the current journal; gave final approval of the version to be published; and agree to be accountable for all aspects of the work. All the authors are eligible to be an author as per the international committee of medical journal editors (ICMJE) requirements/guidelines.

\section{CONFLICTS OF INTEREST}

The authors report no financial or any other conflicts of interest in this work.

\section{ETHICAL APPROVALS}

This study protocol was approved by the University Research Ethics Committee of University Brunei Darussalam (approval reference: UBD/FOS/M2).

\section{PUBLISHER'S NOTE}

This journal remains neutral with regard to jurisdictional claims in published institutional affiliation. 


\section{REFERENCES}

Aguayo-Mazzucato C. \& Bonner-Weir S. Pancreatic $\beta$ cell regeneration as a possible therapy for diabetes. Cell Metab, 2018; 27(1): $57-67$.

Ahmed ABA, Rao AS, Rao MV. In vitro callus and in vivo leaf extract of Gymnema sylvestre stimulate $\beta$-cells regeneration and antidiabetic activity in Wistar rats. Phytomedicine, 2010; 17(13):1033-9.

Asgary S, Parkhideh S, Solhpour S, Madani H, Mahzouni P, Rahimi P. Effect of ethanolic extract of Juglans regia L on blood sugar in diabetes-induced rats. J Med Food, 2008; 11(3):533-8.

Cheekati RR, Rao AS, Vijayaraghavan R. A histological study of alloxan-induced diabetes on experimental male Wistar rats. Natl J Physiol Pharm Pharmacol, 2017; 7(12):1329-34.

Dor Y, Brown J, Martinez OI, Melton DA. Adult pancreatic $\beta$-cells are formed by self-duplication rather than stem-cell differentiation. Nature, 2004; 429:41-6.

Goh MPY, Basri AM, Yasin H, Taha H, Ahmad N. Ethnobotanical review and pharmacological properties of selected medicinal plants in Brunei Darussalam: Litsea elliptica, Dillenia suffruticosa, Dillenia excelsa, Aidia racemosa, Vitex pinnata and Senna alata. Asian Pac J Trop Biomed, 2017; 7(2):173-80.

Hafizur RM, Fatima N, Shaukat S. Immunohistochemical evidence of pancreatic $\beta$-cell regeneration in streptozotocin-induced type 2 diabetic rats treated with Gymnema sylvestre extract. J Cytol Histol, 2015; $6: 342$

Hosseini A, Shafiee-Nick R, Ghorbani A. Pancreatic beta cell protection/regeneration with phytotherapy. Braz J Pharm Sci, 2015; 51(1):1-16.

Jelodar G, Mohsen M, Shahram S. Effect of walnut leaf, coriander and pomegranate on blood glucose and histopathology of pancreas of alloxan induced diabetic rats. Afr J Tradit Complement Altern Med, 2007; 4(3):299-305.

Joseph B, Jini D. Antidiabetic effects of Momordica charantia (bitter melon) and its medicinal potency. Asian Pac J Trop Dis, 2013; 3(2):93-102.

Kamyab H, Hejrati S, Khanavi M, Malihi F, Mohammadirad A, Baeeri M. Hepatic mechanisms of the walnut antidiabetic effect in mice. Cent Eur J Biol, 2010; 5:304-9.

Kanetkar P, Singhal R, Kamat M. Gymnema sylvestre: a memoir. J Clin Biochem Nutr, 2007; 41(2):77-81.

Kaur N, Kishore L, Dahiya RS. Antidiabetic effect of new chromane isolated from Dillenia indica L. leaves in streptozotocin induced diabetic rats. J Funct Foods, 2016; 22:547-55.

Kumar S, Kumar V, Prakash O. Antidiabetic and antihyperlipidemic effects of Dillenia indica (L.) leaves extract. Braz J Pharm Sci, 2011b; 47(2):373-8.
Kumar S, Kumar V, Prakash O. Antidiabetic, hypolipidemic and histopathological analysis of Dillenia indica (L.) leaves extract on alloxan induced diabetic rats. Asian Pac J Trop Med, 2011a; 4(5):347-52.

Kumar S, Kumar V, Prakash O. Enzymes inhibition and antidiabetic effect of isolated constituents from Dillenia indica. BioMed Res Int, 2013; 2013:382063.

Menge BA, Tannapfel A, Belyaev O, Drescher R, Müller C, Uhl W, Schmidt WE, Meier JJ. Partial pancreatectomy in adult humans does not provoke $\beta$-cell regeneration. Diabetes, 2008; 57(1):142-9.

Qinna N, Badwan A. Impact of streptozotocin on altering normal glucose homeostasis during insulin testing in diabetic rats compared to normoglycemic rats. Drug Des Devel Ther. 2015; 9:2515-25.

Quattrocchi U. 2012. CRC World dictionary of medicinal and poisonous plants. New York, NY: CRC Press.

Rankin MM, Kushner JA. Adaptive beta-cell proliferation is severely restricted with advanced age. Diabetes, 2009; 58(6):1365-72.

Singh N, Gupta M. Regeneration of beta cells in islets of Langerhans of pancreas of alloxan diabetic rats by acetone extract of Momordica charantia (Linn.) (bitter gourd) fruits. Indian J Exp Biol, 2007; 45:1055-62.

Smitha VP, Mohan MC, Kandra P, Sravani R, Akondi RB. Screening of antimicrobial and antioxidant potentials of Acacia caesia, Dillenia pentagyna and Buchanania lanzan from Maredumilli forest of India. J Pharm Res, 2012; 5(3):1734-8.

Surya S, Salam AD, Tomy DV, Carla B, Kumar RA, Sunil C. Diabetes mellitus and medicinal plants-a review. Asian Pac J Trop Dis, 2014; 4(5):337-47.

Tan AL, Latiff A. A taxonomic study of Dillenia L. (Dilleniaceae) in Peninsular Malaysia. Malay Nat J, 2014; 66(3):338-53.

Xu X, D’Hoker J, Stangé G, Bonné S, De Leu N, Xiao X, Van De Casteele M, Mellitzer G, Ling Z, Pipeleers D, Bouwens D, Scharfmann R, Gradwohl G, Heimberg H. $\beta$ cells can be generated from endogenous progenitors in injured adult mouse pancreas. Cell, 2008; 132(2):197-207.

Yadav RK, Srivastava SK, Bahadur L, Lall AM, Pal M. Antioxidant and antidiabetic activity of Dillenia pentagyna Roxb. fruit extract. Ann Phytomed, 2017; 6(1):121-6.

Zhou Q, Melton DA. Pancreas regeneration. Nature, 2018; 557(7705):351-8.

\section{How to cite this article:}

Matusin AHA, Ghani NIA, Ahmad N. Pancreatic islet regenerative capability of Dillenia excelsa in alloxan-induced diabetic rats. J Appl Pharm Sci, 2021; 11(03):121-129. 


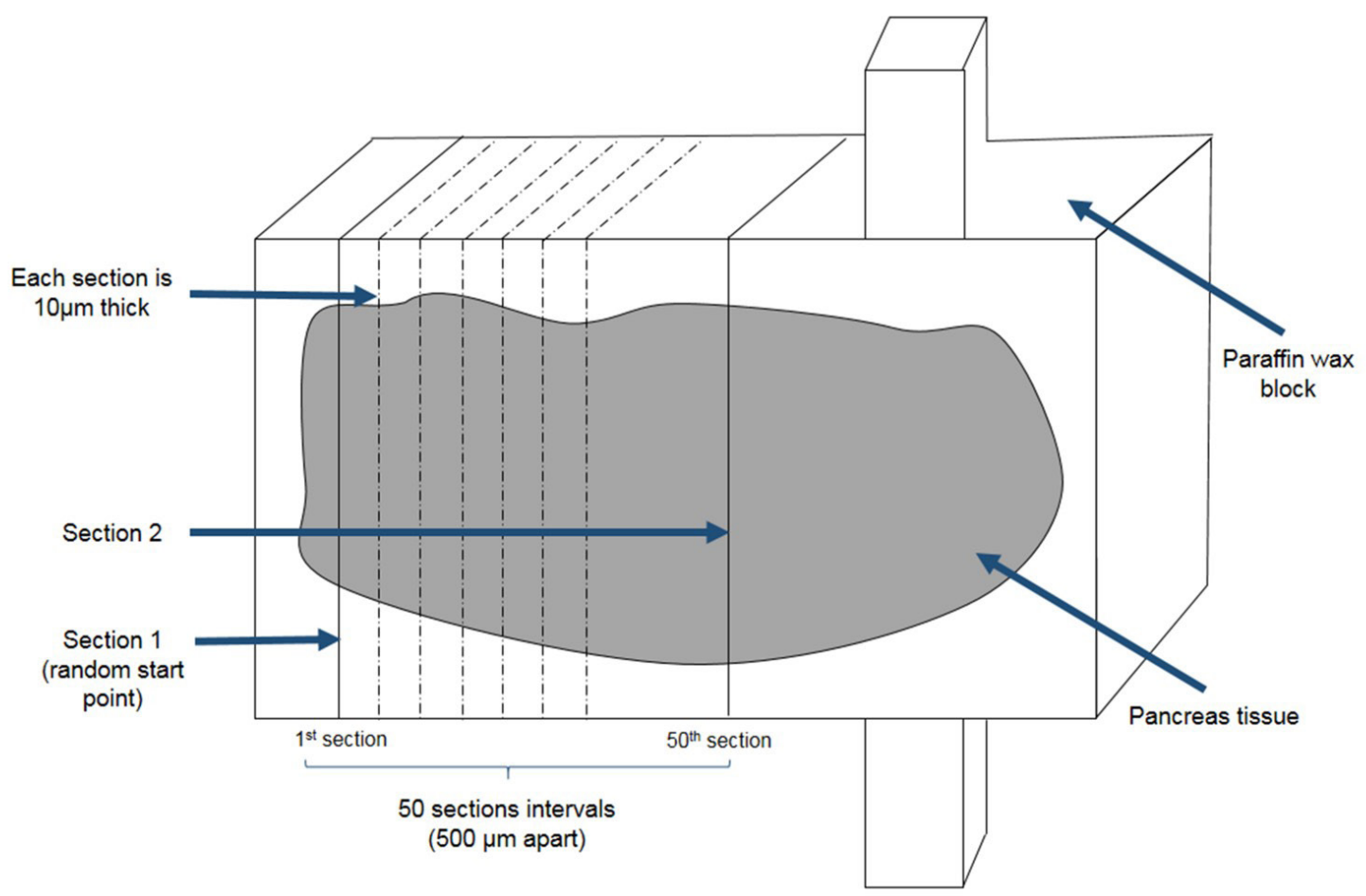

Supplementary Figure 1. Pancreatic tissue sectioning and sampling. Pancreas tissue blocks was sectioned at $10 \mu \mathrm{m}$ thickness. Section 1 was selected from a random start point. Section 2 was sampled from a section that was at least $500 \mu \mathrm{m}$ apart from section 1.

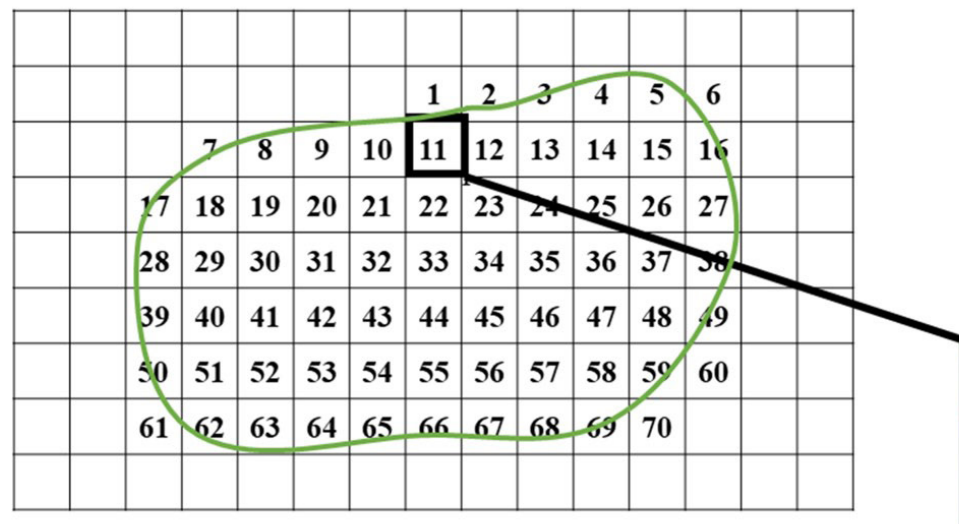

(a)

Supplementary Figure 2. Segmentation of pancreas tissue section. (a) The whole pancreas tissue section was segmented into smaller parts and numbered. All segments that was included in the tissue section were photographed and numbered accordingly for further analysis. (b) An image showing one part of the photographed segments with pancreatic islets. 


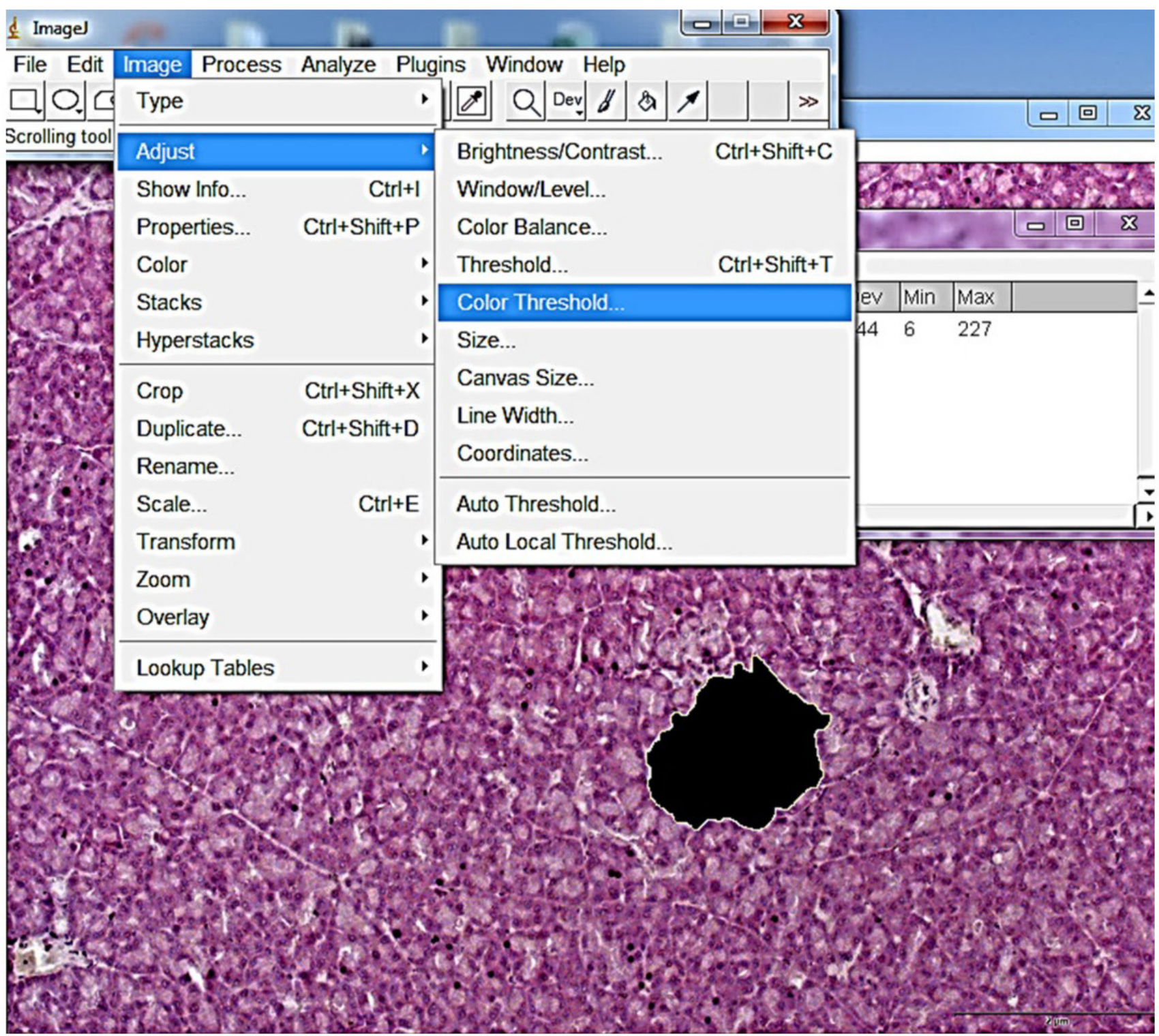

Supplementary Figure 3. Selection of the whole pancreas tissue. Following the measurement of the area of islet, the islet was excluded from the overall measurement of tissue area so that the area measurement of the whole segment can be determined.

Table 1. Blood glucose concentration of animals treated with $D$. excelsa methanolic leaf extract.

\begin{tabular}{|c|c|c|c|c|}
\hline \multirow{2}{*}{ Time (weeks) } & \multicolumn{4}{|c|}{ Blood glucose concentration (mmol/l) } \\
\hline & $\mathbf{0}$ & 4 & 8 & 12 \\
\hline Normal control & $6.10 \pm 0.35$ & $3.77 \pm 0.11$ & $4.82 \pm 0.15$ & $4.38 \pm 0.16$ \\
\hline Alloxan only & $27.10 \pm 0.50$ & $24.60 \pm 3.03$ & $25.75 \pm 1.15$ & $27.63 \pm 0.17$ \\
\hline Alloxan + D. excelsa $250 \mathrm{mg} / \mathrm{kg}$ b.w. & $24.90 \pm 1.46$ & $26.90 \pm 1.05$ & $25.70 \pm 1.19$ & $18.80 \pm 3.29^{\mathrm{b}}$ \\
\hline Alloxan +D. excelsa $500 \mathrm{mg} / \mathrm{kg}$ b.w. & $27.00 \pm 0.79$ & $20.80 \pm 4.06$ & $15.40 \pm 3.67^{\mathrm{a}}$ & $11.60 \pm 1.34^{\mathrm{ab}}$ \\
\hline D. excelsa $250 \mathrm{mg} / \mathrm{kg}$ b.w. + Alloxan & $22.90 \pm 3.69$ & - & - & - \\
\hline D. excelsa $500 \mathrm{mg} / \mathrm{kg}$ b.w. + Alloxan & $11.20 \pm 2.78^{b}$ & - & - & - \\
\hline
\end{tabular}

Data are represented as mean \pm SEM blood glucose concentrations of animals in the normal control $(n=6)$, alloxan-only control $(n=6), D$. excelsa treatment $(n=6)$, and protective groups $(n=5)$. (a) $p<0.05$ indicates a significant difference between the blood glucose levels in week 0 and subsequent weeks of animals in the same group. (b) $p<0.05$ indicates a significant difference between the extract-treated group and alloxan-only control group. 


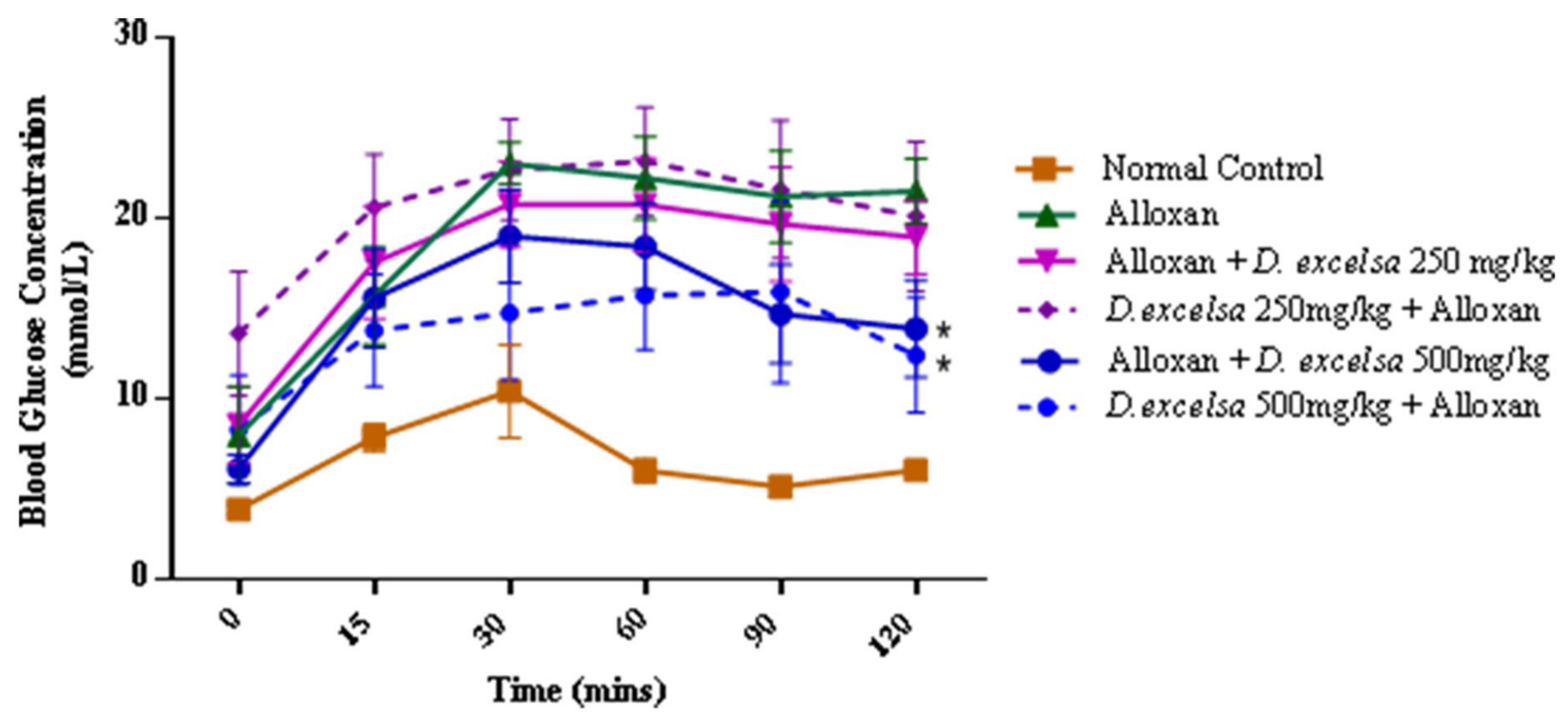

Supplementary Figure 4. The IPGTT blood glucose concentrations of the experimental rats. Data represent mean \pm SEM blood glucose concentration normal control $(\mathrm{n}=6)$, alloxan-only control $(\mathrm{n}=6), D$. excelsa treatment $(\mathrm{n}=6)$ and $D$. excelsa protective groups $(\mathrm{n}=5) .{ }^{*} p<0.05$ indicated a significant difference between the treatment and protective groups and alloxan only control group at 120 minutes.

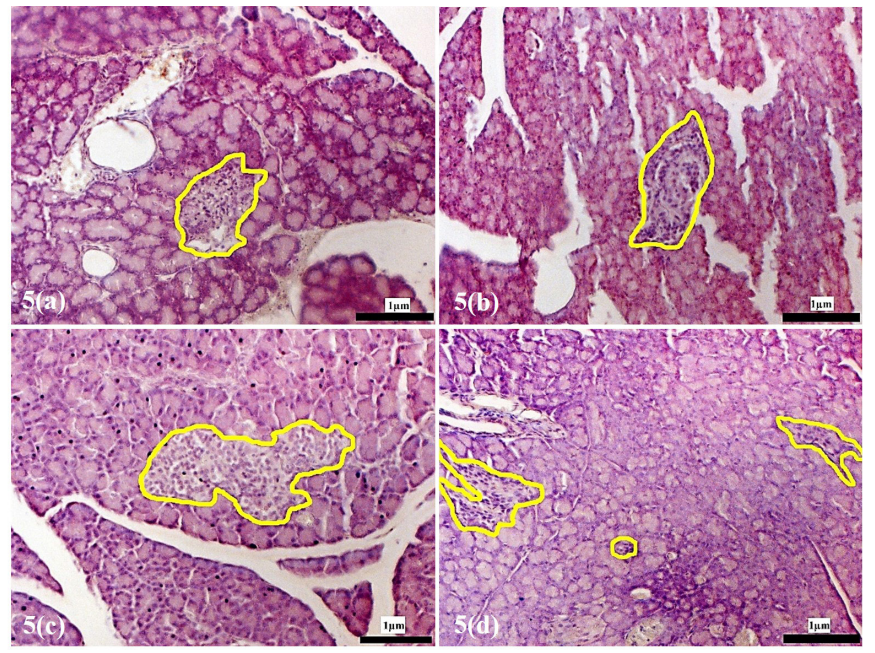

Supplementary Figure 5. Morphology of the pancreatic islets of rats treated with alloxan. (a) Islets morphology after 72 hours of alloxan injection. (b) Islets following alloxan injection, 4 weeks recovery period. (c) 8 weeks recovery post alloxan. (d) 12 weeks recovery post alloxan. The pancreatic islets were outlined in yellow (magnification $\times 200$ ).

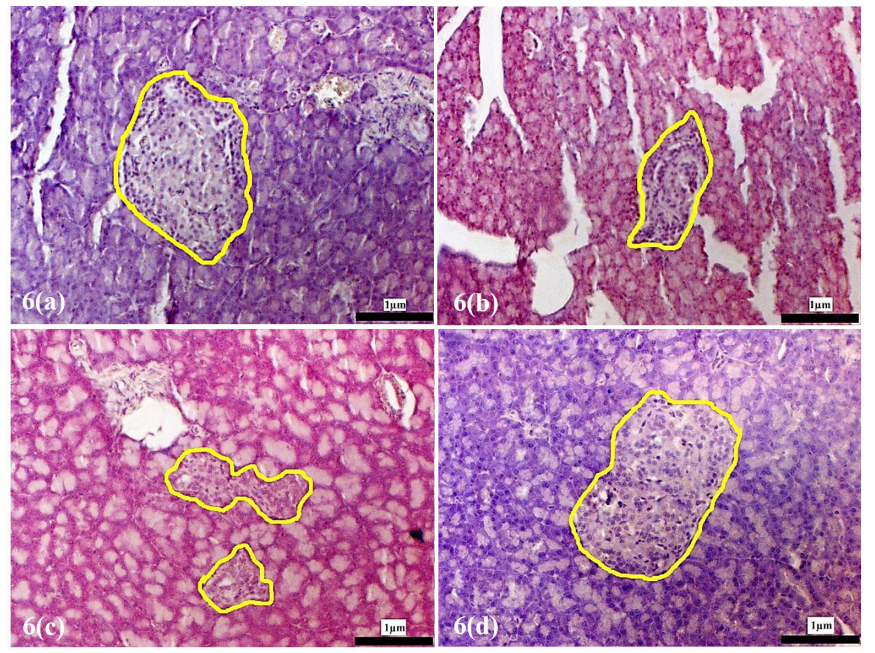

Supplementary Figure 6. Morphology of the pancreatic islets of the experimental rats at 4 weeks following treatment with $D$. excelsa extract. Pancreas tissues were obtained from (a) normal control, (b) alloxan only control, (c) low dose treatment and (d) high dose treatment groups. The pancreatic islets were outlined in yellow (maginification x200). 


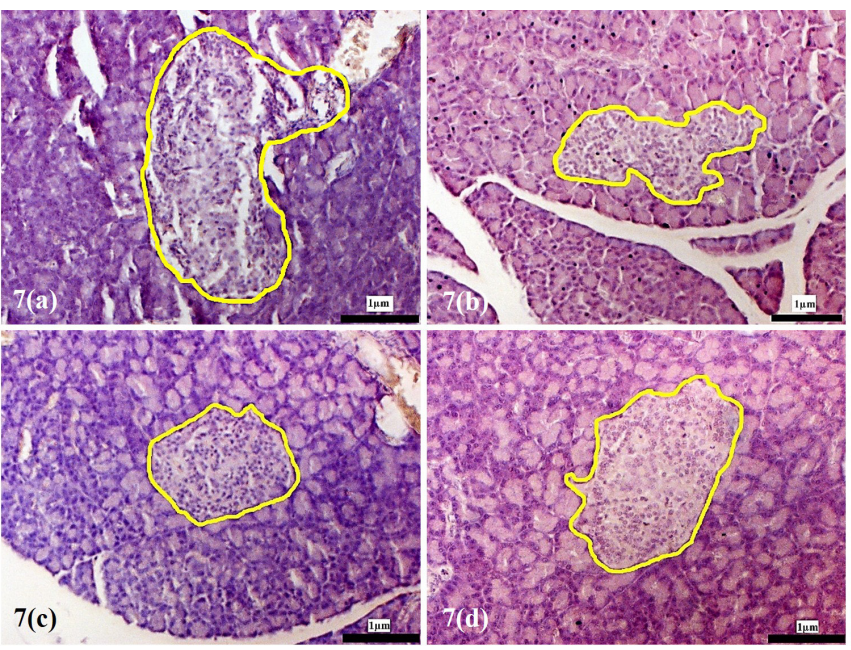

Supplementary Figure 7. Morphology of the pancreatic islets of the experimental rats at 8 weeks following treatment with $D$. excelsa extract. Pancreas tissues were obtained from (a) normal control, (b) alloxan only control, (c) low dose treatment and (d) high dose treatment groups. The pancreatic islets were outlined in yellow (maginification x200).

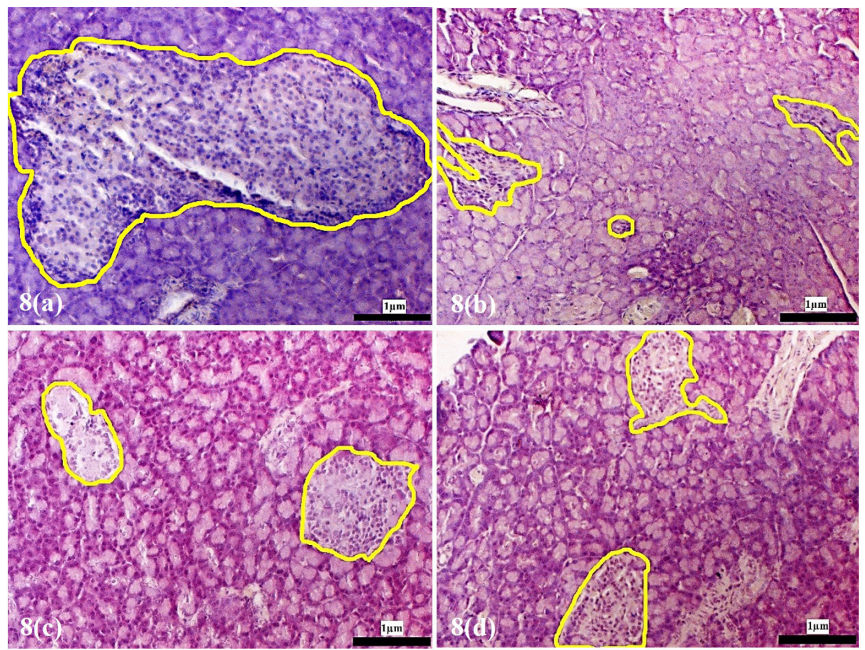

Supplementary Figure 8. Morphology of the pancreatic islets of the experimental rats at 12 weeks following treatment with $D$. excelsa extract. Pancreas tissues were obtained from (a) normal control, (b) alloxan only control, (c) low dose treatment and (d) high dose treatment groups. The pancreatic islets were outlined in yellow (maginification $\mathrm{x} 200$ ).

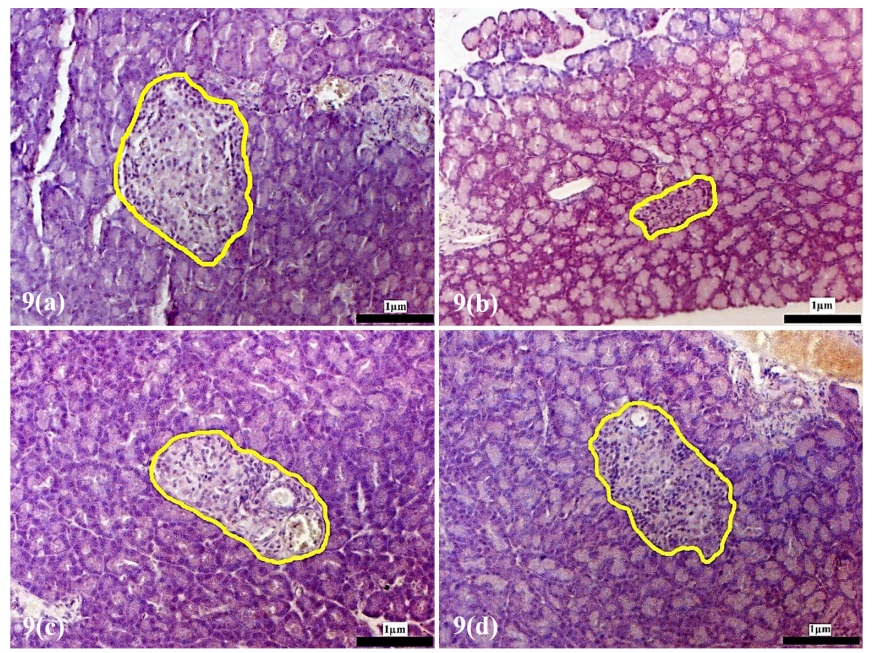

Supplementary Figure 9. Morphology of the pancreatic islets of protective animal group pre-treated with $D$. excelsa leaf extract. Pancreas tissues were obtained from (a) normal control, (b) alloxan only control, (c) low dose protective and (d) high dose protective groups. The pancreatic islets were outlined in yellow maginification $\times 200$ ).

Table 2. Ratio of islet area relative to whole tissue area $\left(\times 10^{-3}\right)$

\begin{tabular}{|c|c|c|c|c|c|c|}
\hline Time (week) & Normal control & Alloxan only control & $\begin{array}{l}\text { Alloxan + D. excelsa } \\
250 \mathrm{mg} / \mathrm{kg} \text { b.w. }\end{array}$ & $\begin{array}{l}\text { Alloxan + D. excelsa } \\
500 \mathrm{mg} / \mathrm{kg} \text { b.w. }\end{array}$ & $\begin{array}{l}\text { D. excelsa } 250 \mathrm{mg} / \mathrm{kg} \\
\text { b.w. + alloxan }\end{array}$ & $\begin{array}{l}\text { D. excelsa } 500 \mathrm{mg} / \mathrm{kg} \\
\text { b.w. + alloxan }\end{array}$ \\
\hline 4 & $4.86 \pm 0.35$ & $2.07 \pm 0.20$ & $2.60 \pm 1.24$ & $4.23 \pm 0.8^{1} \mathrm{a}$ & & - \\
\hline 12 & $6.44 \pm 0.31$ & $2.27 \pm 0.49$ & $3.07 \pm 0.71$ & $4.99 \pm 0.5^{2 \mathrm{a} b}$ & & _- \\
\hline
\end{tabular}

The data are represented as mean \pm SEM. All measurements were obtained from two pancreas tissue sections of each animal in the group $(n=3$ per group). Week 0 (72 hours post-alloxan) represents the control for all animals injected with alloxan. (a) $p<0.05$ indicates a significant difference between the respective week and week 0 of the animals in the same group. (b) $p<$ 0.05 indicates significant difference with the alloxan-only control group within the same time point. 